\title{
A prática pedagógica como fonte de conhecimento
}

\author{
Leide Mara Schmidt ${ }^{1}$ \\ Mariná Holzmann Ribas ${ }^{2}$ \\ Marlene Araújo de Carvalho ${ }^{3}$
}

\begin{abstract}
RESUMO
O pretendido no texto são algumas reflexões sobre a prática pedagógica, a partir do que se vem discutindo em publicações recentes, tendo como fio condutor a formação contínua dos professores. Isto está apresentado em três momentos: no primeiro, tenta-se discutir o conceito de prática na perspectiva dialética. Em seguida estabelecem-se duas diretrizes, já utilizadas por VEIGA (1989): a prática pedagógica repetitiva e a prática pedagógica reflexiva. No segundo momento, tece-se um panorama onde aparecem os problemas da educação e do ensino localizados na escola, que dificultam um trabalho participativo e coletivo. Ao mesmo tempo, chama-se a atenção para a exigência de um novo profissional capaz de responder aos desafios que a sociedade está a exigir. Finalmente, coloca-se a preocupação de educadores e estudiosos de vários países, inclusive do Brasil, sobre a necessidade de mudanças no trabalho docente.
\end{abstract}

Palavras-chave: prática, práxis, prática pedagógica, prática reflexiva, formação de professores, formação contínua, professor reflexivo

\footnotetext{
Professora da Universidade Estadual de Ponta Grossa - Doutoranda do Programa de Estudos Pós-Graduados em Supervisão e Currículo - PUC/sP.

${ }^{2}$ Professora da Universidade Estadual de Ponta Grossa - Doutora do Programa de Estudos PósGraduados em Supervisão e Currículo - PUC/SP.

${ }^{3}$ Professora da Universidade Federal do Piauí -Doutoranda do Programa de Estudos Pós-Graduados em Supervisão e Currículo - PUC/sP.

Olhar de professor, Ponta Grossa, 1(1):9-23, out. 1998.
} 
A proposta deste trabalho é apresentar algumas considerações sobre a prática pedagógica, a partir do que se vem discutindo em publicações recentes, tendo como fio condutor a formação contínua dos professores.

No primeiro momento, tenta-se discutir o conceito de prática na perspectiva dialética tomando por base VÁZQUEZ (1977). Em seguida estabelecem-se duas diretrizes, já utilizadas por VEIGA (1989): a prática pedagógica repetitiva e a prática pedagógica reflexiva.

No segundo momento, tece-se um panorama onde aparecem os problemas da educação e do ensino localizados na escola, que dificultam um trabalho participativo e coletivo. Ao mesmo tempo, chama-se a atenção para a exigência de um novo profissional capaz de responder aos desafios que a sociedade está a exigir.

No terceiro momento, coloca-se a preocupação de educadores e estudiosos de vários países, inclusive do Brasil, sobre a necessidade de mudanças no trabalho docente. Os estudos que estão sendo realizados têm em comum a reflexão sobre o saber de experiência, isto é, a reflexão do professor sobre o seu próprio fazer cotidiano. Todos são unânimes em fazer uma chamada para a necessidade da formação contínua dos professores e para a reorganização dos espaços escolares. Parece estar acontecendo na educação uma revolução copernicana, pois a sociedade está tomando consciência de que a escola não é o único centro formador de consciências. É apenas mais um dentre tantos outros, haja vista a formação nas empresas, a ação das Organizações Não Governamentais - ONGS, principalmente, nos países de terceiro mundo e os espaços oferecidos pela televisão e pela mídia em geral.

Pode-se perceber que essas preocupações vêm no bojo das reformas educacionais que estão sendo implementadas em países da América do Norte, Europa e América Latina.

A prática como fonte geradora de conhecimento implica todo um problema de reflexão que vem sendo pesquisado por diversos estudiosos de diferentes países. O que esses estudos estão indicando é que não está claro para estes pesquisadores como os professores podem se tornar mais capazes; parecem não terem clareza sobre que competências e habilidades são necessárias para que o professor possa fazer o seu trabalho em termos de ensino que a sociedade exige hoje. Está bastante claro que os cursos de formação de professores, da maneira como vêm sendo desenvolvidos, não são suficientes para que o profissional da educação desempenhe, efetivamente, uma prática pedagógica consciente que leve à transformação de si próprio e daqueles que estão sob sua responsabilidade.

Para melhor compreender a prática pedagógica é necessário elucidar o sentido dos termos "prática" e "práxis". 
A palavra prática deriva "do grego praktikós, de prattein, e tem o sentido de agir, realizar, fazer. Diz respeito à ação. Ação que o homem exerce sobre as coisas, aplicação de um conhecimento em uma ação concreta efetiva (JAPIASSU; MARCONDES, 1993, p.199).

Na filosofia marxista, a palavra grega "práxis" é usada "para designar uma relação dialética entre o homem e a natureza, na qual o homem, ao transformar a natureza com seu trabalho, transforma a si mesmo." (Idem, Ibidem, 1993, p.200).

É comum a substituição da palavra prática pela palavra práxis e, ao se fazer tal substituição, pensa-se estar resolvendo um problema teórico. Isso acontece por falta de domínio de "uma categoria de pensamento enquanto instrumento teórico mais elevado e adequado de compreensão da realidade" (RIBEIRO, 1991, p.15).

A prática tem uma dimensão prático-utilitária quando tenta resolver apenas as necessidades imediatas. $\mathrm{O}$ homem comum, segundo VÁZQUEZ (1977, p.11)

Considera a si mesmo como o verdadeiro homem prático; é ele que vive e age praticamente. Dentro de seu mundo as coisas não apenas são e existem em si, como também são e existem, principalmente, por sua significação prática, na medida em que satisfazem necessidades imediatas de sua vida cotidiana (...) o mundo prático - para a consciência comum
- é um mundo de coisas e significação em si.

Sendo assim, de acordo com VÁZQUEZ, o homem comum só concebe a prática como prática-utilitária, isto é, aquilo que ele usa para satisfazer as necessidades imediatas da vida cotidiana.

A práxis, por sua vez, é “ a atividade humana que produz objetos, sem que por outro lado essa atividade seja concebida com o caráter estritamente utilitário que se infere do prático na linguagem comum" (Idem, ibidem, p.5).

Vista nesta perspectiva, a práxis é "a atividade humana transformadora da realidade natural e humana" (Idem, Ibidem, p.32). Tem um caráter consciente e intencional.

Na práxis, o homem compreende a racionalidade da prática. No dizer de Marx, o homem tem olhos para ela, isto é, tem a consciência da realidade.

Em toda forma específica de práxis e na prática tomada em seu conjunto, enquanto práxis total humana, está contida a teoria por se tratar de uma prática de um ser consciente - o que equivale a dizer que se trata de uma prática dirigida por finalidades que são produtos da consciência; finalidades estas que para se efetivarem exigem um mínimo de conhecimento (RIBEIRO, 1991, p.30).

É preciso ter uma consciência elevada da práxis para poder captar e exprimir de modo adequado o verda- 
deiro significado da práxis humana total e de suas manifestações particulares, concretas e específicas, como é o caso da prática pedagógica.

A prática pedagógica, como forma específica de práxis, é uma dimensão da prática social dirigida por objetivos, finalidades e conhecimentos, vinculada com a prática social mais ampla.

A prática pedagógica pressupõe uma relação teórico-prática, pois a teoria e a prática encontram-se em indissolúvel unidade e só por um processo de abstração podemos separálos.

Segundo veiga (1989, p. 17)

O lado teórico é representado por um conjunto de idéias constituído pelas teorias pedagógicas, sistematizado a partir da prática realizada dentro das condições concretas de vida e de trabalho. A finalidade da teoria pedagógica é elaborar ou transformar idealmente, e não realmente, a matéria prima. O lado objetivo da prática pedagógica é constituído pelo conjunto dos meios, o modo pelo qual as teorias pedagógicas são colocadas em ação pelo professor. O que a distingue da teoria é o caráter real, objetivo da matéria prima sobre a qual ela atua, dos meios ou instrumentos com que exerce a ação, e de seu resultado ou produto. Sua finalidade é a transformação real, objetiva de modo natural ou social, satisfazer determinada necessidade humana.

Como atividade humana, a prática pedagógica pode ou se constituir em atividade prática, numa visão utilitarista, ativista e espontaneísta, ou se constituir em uma práxis guiada por intenções conscientes. Dessa forma, ela toma uma dupla diretriz ${ }^{4}$ : de um lado temos uma prática pedagógica repetitiva e, de outro, a prática pedagógica reflexiva.

No primeiro caso, a unidade teoria e prática é rompida, a fragmentação do conhecimento encontra espaço para efetivar-se, havendo dificuldades para a introdução do novo. Nesse terreno, a prática do professor vai-se efetivando num marasmo respaldado pela rígida burocracia e controle escolares.

No cotidiano da atividade docente, as ações parecem acontecer sem dúvidas nem reflexões, num ativismo sem precedentes. Esse ativismo pode levar o professor a alienar-se do seu trabalho e dos seus pares, correndo o risco de não se reconhecer no que realiza. Embora haja nele uma certa consciência - mesmo débil - em relação a sua prática, esta tende a desaparecer pelo caráter mecânico e burocratizado dessa prática.

As condições concretas de trabalho do professor transformam-no no

4 Esquema proposto por VEIGA, 1989. 
último elo de uma cadeia rígida de poder, motivo pelo qual ele se sente impelido a cumprir um papel no qual não se reconhece. Na sala de aula seu trabalho é condicionado pelo regimento escolar, pelas leis do sistema de ensino, pelas relações de emprego e pela formação deficiente e inadequada que possui.

A prática pedagógica reflexiva é aquela enunciada por Paulo Freire: "ninguém educa ninguém, como tampouco ninguém se educa a si mesmo: os homens se educam em comunhão, mediatizados pelo mundo" (FREIRE, 1975, p.9). Isso significa que o processo de conscientização se desenvolve na medida em que as pessoas, em grupo, discutem e enfrentam problemas comuns.

A prática pedagógica reflexiva tem como ponto de partida e chegada a prática social. Caracteriza-se pela indissolubilidade entre teoria e prática, em que as dicotomias tendem a desaparecer. Tendo um caráter inquieto, criador e acentuado grau de consciência, a prática pedagógica tem como preocupação produzir mudanças qualitativas e, para isto, procura munir-se de um conhecimento crítico e aprofundado da realidade.

Esta dimensão pedagógica está fundada num caráter epistemológico: e o conhecimento não se dá pela transmissão de um conceito abstrato de uma pessoa para outra, nem a partir de instituições de individuos isolados; o conhecimento ocorre no bojo do pro- cesso histórico e coletivo da práxis. No processo de transformação da natureza e da própria sociedade, os homens elaboram teorias a partir e em função da prática, nesta se verificando também o sentido e o valor da teoria (FLEURI, 1992, p. 29).

Essa prática está marcada por uma opção consciente, pelo desejo de renovação, de transformação e de mudanças, pela busca e implementação de novos valores que venham a dar uma nova direção à prática social.

Pode-se identificar tais marcas naqueles que buscam uma sociedade mais justa e de melhores oportunidades para todos.

A prática pedagógica, nesse contexto, caracteriza-se como fonte de conhecimento e geradora de novos conhecimentos. Nessa perspectiva, o novo encontra aqui o nicho ideal para vicejar e expandir-se.

Sabe-se que o sistema de ensino e as escolas encontram-se estruturados de modo fragmentado, setorizado, centralizado. A estrutura de poder no sistema de ensino faz com que as decisões de Estado, de escola, de cursos, ou mesmo de disciplina, sejam tomadas de forma centralizada e de cima para baixo, sem a participação da maioria que está na base e que sofre a ação resultante das mais variadas propostas. O mesmo sistema é organizado por setores e departamentos que não se relacionam entre si. $\mathrm{O}$ currículo e os programas são fragmentados em graus, cursos e disciplinas, 
de tal forma que passam a ser assumidos como estanques e sem relação crítica entre si.

Predomina, assim, uma estrutura que, de muitas formas, dificulta a união entre as pessoas para discutirem e enfrentarem conjuntamente seus problemas comuns; são muitas as resistências que se colocam ao surgimento de grupos no espaço da escola. Sabe-se que somente ações coletivas e planejadas podem produzir alguma transformação significativa nas relações sociais de poder, no sistema de ensino e na escola.

A escola tem a função de transmitir o conhecimento socialmente construído, elaborado e sistematizado a todos os cidadãos.

Mas como é geralmente concebido esse conhecimento na prática escolar?

A prática fragmentada de elaboração do conhecimento determina um distanciamento da realidade também crescente. Na medida em que se focalizam apenas aspectos isolados da realidade, existe maior dificuldade em compreendê-la totalmente, e quase não se conseguindo enfrentar de modo orgânico seus problemas fundamentais.

A fragmentação do conhecimento e o seu distanciamento da realidade concreta tornam o conhecimento elaborado acessível apenas a "especialistas", cada um em sua área específica. Desse modo, o conhecimento especializado passa a ser considerado como coisa, como objeto de posse por parte de algumas pessoas, que passam a ter o direito de decidir como seu conhecimento deve ser utilizado ou assimilado pelos outros. Criam-se então, na vida cotidiana, relações de dependência das pessoas que detêm esses conhecimentos, para com aquelas que detêm frações do saber.

Sendo assim, considerado detentor de uma parte do saber, o professor é pago para trabalhá-lo com os alunos. E se é ele quem conhece, será ele quem deve resolver como passar seu conhecimento, isto é, só o professor é que tem condições de programar, controlar e avaliar a transmissão do seu saber. Os alunos não passam de simples receptores deste conhecimento.

Esse tipo de relação pedagógica que considera o professor como sujeito que deposita seu saber-objeto na cabeça vazia do aluno legitima-se por uma inversão do processo de conhecimento e se dá, pelo menos, em três circunstâncias: primeiro, pelo entendimento da teoria como separada da prática. Na realidade, toda teoria é construída a partir e em função da prática e sua validade se constata em confronto com a prática. Segundo, divide-se a teoria em várias áreas e segmentos estanques. Tudo, porém, se relaciona e a visão da realidade só é crítica na medida em que se articulem dialeticamente os enfoques e as diferentes dimensões da realidade. Terceiro, toma-se frações do conhecimento como objeto de posse de pessoas. O conhecimento, no entanto, é 
um processo de representação do real, construído socialmente através da história e da cultura de povos de diferentes nações.

Ainda, há dificuldades de se perceber o conhecimento como autoconhecimento, o conhecimento como local e total.

A coisificação do saber representa, então, uma maneira falsa de se entender e de se transmitir o conhecimento. E, na escola, esta falsificação do saber elaborado serve para escamotear e legitimar a relação de poder que se constata entre professor e aluno.

Sendo assim, percebemos que na escola não se considera toda a evolução do conhecimento, todo o potencial do conhecimento produzido, que é dinâmico, mantendo sempre grande relação com todas as áreas. A escola, o professor, não estão valorizando toda a informação que existe no mundo hoje. Estão muito mais preocupados com o saber produzido como verdade, cristalizado, acabado, não entendendo que o conhecimento é provisório e que não é dado ou findo; ao contrário, está sempre em construção. Como diz Nilda ALVES (1992, p.76):

Se a partícula mais íntima da matéria está em movimento permanente, se a natureza está em contínuo movimento, se os homens são seres em movimento constante em sua luta por sobreviver e por conviver, como poderia o conhecimento, e apenas o conhecimen- to, ser estático? Falar em verdade absoluta é acreditar na finalidade do conhecimento. Como um conhecimento finito poderia dar conta da infinitude do real? Se o olhar do sujeito modifica o objeto, como conceber que o conhecimento produzido na tensão sujeito em movimento e objeto em movimento seja estático?

A situação da escola não pode permanecer como se apresenta, tanto no aspecto estrutural ou organizacional, quanto no aspecto de conceber e tratar o conhecimento; é urgente que seja modificada. São tão grandes os desafios do mundo de hoje para a educação que se precisa procurar caminhos, saídas eficientes. Tem-se que agir; não se pode continuar esperando que as soluções venham de cima para baixo, não se pode ficar alheio a todas essas mudanças sociais e culturais que aí estão e abalaram definitivamente as necessidades das pessoas quanto à sua formação e qualificação para o trabalho. Novas maneiras de agir surgem como forma de ultrapassagem, de enfren-tamento de novas situações. Não se pode deixar de perceber que novas formas de vida, de relação, de transporte, de lazer, novos padrões éticos estão sendo forjados pelas culturas pós-industriais. É preciso ter presente que o momento histórico, cultural, social e político exige do ser humano grande operacionalidade de pensamento, habilidades e atitudes próprias em vir- 
tude do avanço tecnológico tão rápido e intenso.

A vida hoje na escola, na sala de aula, tem que ser muito mais do que a transmissão de um conteúdo sistematizado do saber. Deve, com certeza, incluir a aquisição de hábitos e habilidades e a formação de uma atitude correta frente ao próprio conhecimento, uma vez que o aluno deverá ser capaz de ampliá-lo e reconstrui-lo quando necessário, além de aplicá-lo em situações próprias do seu contexto de vida.

Sendo assim, é preciso que o professor enfrente o desafio de compreender os tempos novos para abarcar os anseios das novas gerações e auscultar os rumos do futuro. Para isso é necessário "dialogar com a realidade inserindo-se nela como sujeito criativo" (DEMO, 1993, p.21), para formar o sujeito histórico capaz de definir o seu destino e nele participar ativamente, uma vez que a formação básica "tem como finalidade principal dotar a pessoa da característica de pensar crítica e criativamente, e de manterse em estado ininterrupto de atualização" (Idem, Ibidem, p.33), levando em conta que "a alma da formação básica é aprender, saber pensar, informar-se e refazer todo o dia a informação, questionar. Conhecimentos pertinentes e sobretudo seu manejo propedêutico são base para o exercício do papel do sujeito participativo e produtivo" (Idem, Ibidem, p.89).

Diante disso, é preciso que o professor tenha e esteja bem consciente de que:

(...) ensinar já não significa transferir pacotes sucateados, nem mesmo significa meramente repassar o saber. Seu conteúdo correto é motivar o processo emancipatório com base em saber crítico, criativo, atualizado, competente. Trata-se, não de cercear, temer, controlar a competência de quem aprende, mas de abrir-lhe a chance na dimensão maior possível. Não interessa o discípulo mas o novo mestre. Entre o professor e o aluno não se estabelece apenas hierarquização verticalizada, que divide papéis pela forma do autoritarismo, mas sobretudo confronto dialético. Este alimenta-se da realidade histórica formada por entidades concretas que se relacionam de modo autônomo, como sujeitos sociais plenos (Idem, Ibidem, p.153).

Infelizmente, como já se viu e a experiência mostra, não é assim que o trabalho do professor se dá na escola. O professor ainda está arraigado ao modelo de sua formação e poucos percebem que muitos dos problemas que surgem em sala de aula, e na escola como um todo, estão em função da própria ação docente diante do conhecimento. Não resolve querer-se camuflar todas as dificuldades que se encontram no trabalho com os alunos, como: desinteresse, indisciplina, não permanência na escola, desagrado pela escola, falta de estudo, desinteresse da família, repetência, condições 
econômicas precárias, e procurar atribuir sempre a responsabilidade a causas externas. Alguma coisa tem-se que fazer no sentido de entender esses condicionantes, que não deixam de ser influentes, e que, por isso mesmo, tornam o trabalho na escola mais difícil. Considerando todos esses aspectos é que a escola tem um complexo trabalho para fazer, que exige muito mais da habilidade do professor e que a sua formação deve garantir.

Sendo assim, a formação do professor tem que ser repensada. Mas o que fazer com esse mestre que já está atuando na escola? O momento histórico está a exigir outra mentalidade, outro modo de ser e de agir. Será que o professor não teria que ser levado a repensar o seu papel? O que lhe cabe de fato, hoje, como professor? Que é ser professor? Qual a sua responsabilidade? Onde se localiza o cerne de seu trabalho?

Hoje tem-se que admitir que apenas a transmissão do conhecimento não é o que deve marcar ou justificar o trabalho do professor; então o que é?

Diante desse problema e desse tipo de questionamento, a tendência natural dos sistemas de ensino é admitir que a qualidade de ensino passa pela competência ou incompetência do professor, e, então, tentar qualificálo. Entretanto, qualificá-lo tem significado sempre investir mais em reciclagem, cursos de atualização, cursos a distância. Isto porque o pressuposto é que o professor está despreparado em termos de conteúdos curriculares, conteúdos de aprendizagem e que precisa estar mais atualizado com esses conhecimentos; precisa entender melhor as implicações do processo ensino-aprendizagem, ou ainda porque ele está utilizando uma metodologia inadequada para trabalhar com os alunos atuais. Passa-se então, nesses eventos, a trabalhar conteúdos de ensino com o professor ainda na mesma perspectiva tradicional, atualmente inadequada. A mesma que ele já usou com seus alunos, ou então, trabalha-se a questão metodológica mostrando que a maneira de abordar o aluno tem que ser modificada, quando o cerne da questão está no trabalhar o conhecimento como mola central dentro da escola.

É verdade que, de alguma forma, e talvez mesmo porque a formação do professor seja frágil, ele está com os seus conhecimentos defasados e além de tudo tem pouquíssimas oportunidades de atualização. Quando tem chances de que isto aconteça, quase sempre é de maneira pouco adequada.

E como diz MELLo :

(..) os resultados de estudos sobre a efetividade dos programas de capacitação docente para melhorar a aprendizagem dos alunos não são alentadores.

Se é sustentável o pressuposto de que a capacitação pode ser melhor potencializada numa efetiva interação com a organização es- 
colar, as estratégias e formato desses programas deveria ser repensados (1991, p.36).

Entende-se que é preciso trabalhar com o professor, há necessidade de construção de uma nova competência pedagógica, de aperfeiçoamento de recursos humanos, de capacitação em serviço ou, nas palavras de Ruth PEREIRA, de educação em serviço, entendendo-se por isso:

(...) todas as atividades nas quais os profissionais se envolvem quando estão em serviço e que são estruturadas para contribuir para a melhoria do seu desempenho.

(...) é uma atividade que possui objetivo definido e está comprometida com mudanças em indivíduos ou sistemas organizacionais. Isto é alcançado através de mudanças nas pessoas e não em regras, estruturas, funções ou ambiente físico (embora tudo isso possa estar relacionado a essas mudanças) e levado a efeito através de seu aperfeiçoamento contínuo. (1993, p. 38-39)

Em função dessas considerações, é possível entender que uma nova competência pedagógica se origine na própria prática, no debruçar-se sobre ela, no movimento dialético ação-reflexão-ação. Busca-se escapar da dicotomia entre teoria e prática, evitando a simples justaposição ou associação que encaminharia para uma atitude apenas funcional, operativa.

Tanto a teoria quanto a prática têm papel assegurado nesse processo por- que as teorias são como mapas que nos ajudam a viajar sobre o momento presente para auscultar a realidade, $\mathrm{o}$ que não se faz sem a história. O que se busca na verdade, é a construção de uma prática pedagógica reflexiva, crítica e criativa. Além disso, devese considerar que o planejamento de programas de formação em serviço exige a definição do papel do professor e a respectiva competência dele exigida, das abordagens de currículo no sentido mais moderno dos conhecimentos exigidos hoje e interesses dos profissionais envolvidos. Isso é fundamental tendo em vista que durante a vida profissional ocorre a participação direta na elaboração/ reelaboração do saber e do acelerado desenvolvimento tecnológico por que passa a sociedade. Portanto, a melhor maneira de construir a competência pedagógica é possuir a instrumentação para viver/conviver com as mudanças no contexto educacional e social. Isso porque o educador deve estar alerta para segurança/insegurança, certeza/incerteza, equilíbrio/ desequilíbrio na construção do novo.

Por tudo isso, é necessário que haja uma ação coletiva que permita a discussão do conhecimento, a troca de pontos de vista diferenciados, de modo a permitir o confronto, e a partir daí a imersão em confluências amadurecendo perspectivas para o surgimento de uma nova competência, tanto dos profissionais quanto da escola, é o que se pretende. A escola visualizada como espaço de formação 
dos profissionais do ensino; como locus de aperfeiçoamento que possibilita o encontro sistemático de seus membros para que discutam e reflitam sobre a construção do conhecimento, sobre os problemas do seu cotidiano; como espaço a ser redirecionado, o que requerer, sem dúvida, um movimento de reorganização da própria escola.

Lamenta-se profundamente que a escola não acompanhe a ciência e a tecnologia quando deveria estar à frente, oferecendo condições para tais conquistas.

Diante desse horizonte, salta aos

olhos que necessitamos de uma educação muito diferente daquela usual. Em primeiro lugar, precisamos de educação que puxe o desenvolvimento, não que se arraste atrás, representando o atraso. Para tanto, carece corresponder ao desafio de manejar e produzir conhecimento, ou seja, deve superar a exclusividade da didática ensino-aprendizagem, tipicamente reprodutiva/transmissiva. Trata-se de superar a exclusividade, porquanto continua relevante a função da escola no sentido de socializar conhecimento disponível. (DEMO, 1992, p.24)

Para tal desafio, se faz necessário e urgente trabalhar com os professores de forma que eles entendam que o conhecimento hoje se apresenta diferente, exigindo, principalmente, uma mudança na forma de perceber e com- preender o conhecimento existente no contexto que a modernidade está a exigir; é uma nova dimensão de vida que se impõe.

Posto esse quadro, no qual as idiossincrasias da profissão docente aparecem em suas linhas gerais, não discordamos de NÓvOA (1992, p. 15) quando discorre sobre os aspectos que devem ser considerados à implementação de estratégias de formação de professores.

Colocando a problemática da formação de professores no quadro de dificuldades crescentes, NÓVOA (1992, p.23) pontua o desprestígio da profissão em Portugal. Diz que "aos olhos dos outros, a profissão docente tornou-se difícil de viver do interior (...) a ausência de um projecto coletivo, mobilizador do conjunto da classe docente, dificultou a afirmação social dos professores, dando azo a uma atitude defensiva mais própria de funcionários do que de profissionais autônomos".

NÓVOA entende e defende a formação dos professores como um contínuo fundamental na vida desses agentes e das escolas. Dessa forma, ele sugere que a formação docente voltese para o desenvolvimento pessoal: produzir a vida do professor, ao desenvolvimento profissional: produzir a profissão docente; e ao desenvolvimento organizacional: produzir a escola.

Essa sugestão tem encontrado ressonâncias no pensamento de outros educadores, porque como NóvoA, eles 
sabem que:

A formação de professores tem ignorado, sistematicamente, o desenvolvimento pessoal, confundindo formar e formar-se, não compreendendo que a lógica da actividade educativa nem sempre coincide com as dinâmicas próprias da formação. Mas também não tem valorizado uma articulação entre a formação e os projectos das escolas, consideradas como organizações dotadas de margens de autonomia e de decisão de dia para dia mais importantes. Estes dois esquecimentos inviabilizam que a formação tenha como eixo de referência o desenvolvimento profissional dos professores, na dupla perspectiva do professor individual e do coletivo docente. (1992, p. 24)

Essa pode ser considerada uma boa justificativa para a formação de professores nos moldes sugeridos por NóvoA. O que ele entende ser o Desenvolvimento Pessoal (produzir a vida do professor) é a formação nesse nível, no qual o professor, no quadro de sua história de vida exerce a reflexão e a crítica. Para reforçar esta posição, o autor diz que a formação se constrói “(...) através de um trabalho de reflexividade crítica sobre as práticas e de (re)construção permanente de uma identidade pessoal. Por isso é tão importante investir na pessoa e dar um estatuto de saber à $e x$ periência" (1992, p. 25). Os percursos educativos desse profissional de- vem estar na ordem do dia para que ele possa aprender com o saber da experiência. A troca dessas experiências vão consolidar espaços de formação mútua ; no entanto, a organização das escolas tem desencorajado essa parceria.

A partir dessas constatações, NóvoA (1992, p.26) acredita que o conhecimento-na-ação, a reflexãona-ação e a reflexão sobre-a-ação e sobre a reflexão-na-ação-movimentos sugeridos por SCHÖN (1990) - ganham pertinência no quadro do desenvolvimento pessoal dos professores. "Os momentos de balanço retrospectivo sobre os percursos pessoais e profissionais são momentos em que cada um produz a sua vida, o que, no caso dos professores, é também produzir a sua profissão".

O Desenvolvimento Profissional (produzir a profissão docente) não se dá separado do quadro das histórias de vida do professor. Na perspectiva de paradigmas de formação contínua, as práticas de formação devem tomar como referência as dimensões coletivas e participativas de trabalho, na esperança de que estas práticas contribuam para a conscientização, consolidação e autonomia profissional na "produção dos seus saberes e dos seus valores"(Idem, Ibidem, p.27).

É provável que o interesse mantido pelo próprio desenvolvimento possa estimular estes professores a envidar esforços para enriquecer o seu cabedal de conhecimentos, no "quadro de uma autonomia contextua- 
lizada da profissão docente" (Idem, Ibidem, p. 27).

Isso pode, inclusive, fazer com que muitos destes agentes passem a assumir a responsabilidade da sua própria formação, nos espaços que eles possam ir conquistando no percurso do seu desenvolvimento profissional.

Parece estar-se caminhando no sentido de que os professores assumam-se "como produtores da sua profissão" (Idem, Ibidem, p.28). Sabe-se, entretanto, que os espaços de atuação desses profissionais devem também ser mudados.

Se a formação de professores é encarada como um dos componentes da mudança, esta não se dá sem que os outros contextos em que eles intervêm sejam alterados. O Desenvolvimento Organizacional (produzir a escola) vai depender de como é desenvolvida a formação do seu pessoal. Nenhuma mudança inovadora e transformadora na vida e na profissão docente vai deixar imune a escola, pois a mudança neste setor vai, inevitavelmente, transformar as organizações escolares e seu desenvolvimento. As mudanças qualitativas, no desenvolvimento pessoal e profissional, no coletivo dos professores, se acontecerem, é porque a escola também está produzindo transformações qualitativas no seu interior, as quais, quando se originam de projetos de ação, ajudam a consolidar alguns ganhos, partindo para muitos acertos, quando há uma preocupação em se avaliar o processo desenvolvido pela escola e por seus membros.

Outro educador preocupado com a mudança na escola e na prática docente é Ken ZEICKNER (In: NÓVOA, 1992). ele anuncia as inovações sobre a formação docente no practicum, isto é "momentos estru-turados da prática pedagógica (estágio, aula prática, tirocínio) integrados nos programas de formação de professores" (p.117). Seus estudos, como diretor de programas de formação de professores do ensino básico na Universidade de Wiscosin - Madison, envolvem investigações sobre esses momentos estruturados da prática pedagógica, consolidados nas instituições formadoras.

Esses estudos, centrados na investigação do practicum, têm como preocupação o ensino como prática reflexiva. Nesse sentido SCHÖN (In: NÓvOA, 1992,p.125) fornece bases para o trabalho de Zeichner, com os conceitos de reflexão-na-ação, reflexão-sobre-a-ação e sobre a reflexãosobre-a-ação. "A reflexão-na-ação refere-se aos processos de pensamento que se realizam no decorrer da ação (...); a reflexão-sobre-a-ação, referese ao processo de pensamento que ocorre retrospectivamente sobre uma situação problemática e sobre as reflexão-na-ação produzidas pelo professor". Sobre a reflexão-na-ação, parece uma retrospectiva que o professor faz em direção às reflexões anteriormente realizadas, nos dois movimentos citados. SCHÖN (Idem, 
Ibidem, p. 83), sobre este movimento, diz que: "Após a aula, o professor pode pensar no que aconteceu, no que observou, no significado que lhe deu e na eventual adoção de outros sentidos. Refletir sobre a reflexão-na-ação é uma ação, uma observação e uma descrição que exige o uso de palavras".

Todos esses movimentos parecem navegar na direção do professor para que tome suas práticas cotidianas como objeto de investigação, de reflexão e criação do novo.

PERRENOUD (1993, p.11), em estudos recentes, segue a mesma linha de NóvOA, afirmando que: "Só é possível a formação dos professores pensando e repensando constantemente, à luz das ciências humanas - de todas as ciências humanas - as práticas pedagógicas e o funcionamento dos estabelecimentos de ensino e dos sistemas educativos".

Nos textos examinados, o mesmo autor indica pistas - a utilização do tempo escolar, a prática como rotina em ação, o habitus - para que sejam examinadas, a fim de que as práticas pedagógicas se tornem claras e, assim, possam ser melhor compreendidas e desenvolvidas.

No Brasil, as preocupações com a formação de professores disseminase, mas é na regiões Sudeste e Sul do país que as discussões são veementes. No momento, tem-se notícias de que Maria Izabel da Cunha, Maria da Graça Nicoletti Mizukami, Pedro Demo e Luís Carlos de Freitas - para citar apenas alguns - estão publicando trabalhos sobre o assunto.

Naturalmente, tem-se a convicção de que, nas questões relacionadas com a formação de professores e suas práticas há todo um caminho a percorrer, permeado de dúvidas e de incertezas. No entanto, sabe-se que é necessário acreditar que esse caminho possa ser percorrido com todas as dificuldades que nele se apresentam. Não é tarefa das mais fáceis, mas, seguindo as pegadas de FREIRE e SHOR (1986, p. 56), concorda-se que é preciso "ousar para criarmos e recriarmos com nossos alunos o conhecimento, pela dúvida e pela criticidade".

\section{REFERÊNCIAS BIBLIOGRÁFICAS}

1 ALVES, Nilda (org.). Formação de professores: pensar e fazer. São Paulo: Cortez, 1992.

2 CANDAU, Vera Maria (org.). Rumo a uma nova didática. Petrópolis: Vozes, 1988.

3 COSTA, Marisa C.V. Estudos e pesquisas sobre trabalho docente: panorama das principais tendências. (Versão preliminar). Goiânia. VII ENDIPE, 1994 (mimeo).

4 CUNHA, Maria Izabel da; FERNANDES, Cleoni Maria B. Formação continuada de professores universitários: uma experiência na perspectiva da produção do conheci- 
mento. Educação Brasileira. Brasília, v.16, n.32, jan.jul. 1994.

5 DEMO, Pedro. Desafios modernos da educação. Petrópolis: Vozes, 1993.

6 DOWBOR, Ladislau. O espaço do conhecimento. In: A revolução tecnológica e os novos paradigmas da sociedade. Belo Horizonte: São Paulo: Oficina de Livros IPSO, 1994.

7 FLEURI, Reinaldo M. Educar para quê? São Paulo: Cortez, 1992.

8 FREIRE, Paulo. Conscientização: teoria e prática da libertação. São Paulo: Cortez e Moraes, 1979.

9 JAPIASSU, H.; MARCONDES, D. Dicionário básico de filosofia. 2.ed. Rio de Janeiro: Zahar, 1993.

10 LUPORINI, T.J.; MARTINS, R.B.; RIBAS, M.H. Escola Básica: dois segmentos dissociados. Relatório de pesquisa. UEPG. Ponta Grossa, 1993.

11 MELLO, Guiomar N. de. Políticas públicas de educação. In: Estudos Avançados. São Paulo, v.5, n.13, p.7-47, set./dez. 1991.

12 NÓVOA, António (coord.). Os professores e sua formação. Lisboa: Dom Quixote/ IIE, 1992.

13 PEREIRA, Ruth da C. Educação em serviço para o professor: conceitos e propósitos. Tecno- logia Educacional. Rio de Janeiro, v.22, n.110/111, p.3741, mar./abr. 1993.

14 PERRENOUD, Philippe. Práticas pedagógicas, profissão docente e formação. Lisboa: Dom Quixote/IIE, 1993.

15 RIBEIRO, Maria L.S. Educação escolar e práxis. São Paulo: Iglu, 1991.

16 SHOR, I.; FREIRE, P. Medo e ousadia: o cotidiano do professor. Rio de Janeiro: Paz e Terra, 1986.

17 VÁZQUEZ, A. S. Filosofia da praxis. Rio de Janeiro: Paz e Terra, 1977.

18 VEIGA, Ilma P.A. A prática pedagógica do professor de didática. Campinas: Papirus, 1989. 